\title{
Plantas de cobertura, manejo da palhada e produtividade da mamoneira no sistema plantio direto ${ }^{1}$
}

\author{
Cover crops, straw mulch management and castor bean yield in no-tillage system
}

\author{
Jayme Ferrari Neto², Carlos Alexandre Costa Crusciol ${ }^{3}$, Rogério Peres Soratto ${ }^{3 *}$ e Claudio Hideo Martins da \\ Costa $^{2}$
}

\begin{abstract}
Resumo - Espécies de cobertura que apresentem elevada produção de fitomassa e reciclagem de nutrientes são essenciais para maximizar a produtividade das culturas em sucessão, no sistema plantio direto. O presente trabalho teve por objetivo avaliar a produção de massa de matéria seca e o acúmulo de nutrientes pelo guandu-anão (Cajanus cajan) e o milheto (Pennisetum glaucum), em cultivo solteiro e consorciado, e o efeito do manejo mecânico da palhada na produtividade da mamoneira de safrinha, na fase de implantação do sistema plantio direto. O experimento foi instalado em um Nitossolo Vermelho, em Botucatu, SP. O delineamento foi o de blocos ao acaso, em parcelas subdivididas, com quatro repetições. As parcelas foram constituídas por três coberturas vegetais (guandu-anão, milheto e o cultivo consorciado das duas espécies) e as subparcelas pela ausência ou presença do manejo mecânico da palhada com triturador horizontal, 20 dias após o manejo químico. O milheto solteiro produziu maior quantidade de massa de matéria seca $\left(14.040 \mathrm{~kg} \mathrm{ha}^{-1}\right)$, apresentou maiores concentrações de $\mathrm{K}$ e $\mathrm{Mg}$ e acumulou maiores quantidades de macronutrientes na parte aérea. A mamoneira apresentou maior produtividade de grãos em sucessão ao consórcio guandu-anão + milheto. A produtividade de grãos da mamoneira foi maior na ausência do manejo mecânico da palhada.
\end{abstract}

Palavras-chave - Ricinus communis. Cajanus cajan. Ciclagem de nutrientes. Pennisetum glaucum. Cultivo consorciado. Solos-manejo.

\begin{abstract}
Cover crops that have high phytomass production and nutrient cycling are essential to maximize the crop yields in succession under no-tillage system. This study aimed to evaluate dry matter production and nutrients accumulation by pigeonpea (Cajanus cajan) and pearl millet (Pennisetum glaucum), in sole crop and intercropped, and the effect of straw mulch mechanical management on out-of-season castor bean performance, in no-tillage system establishment. The experiment was carried out on a Rhodic Nitisol, in Botucatu, SP, Brazil. A randomized blocks design, in a split-plot scheme, with four replications, was used. Plots were composed by cover crops (pigeonpea, pearl millet, and pigeonpea-pearl millet intercropping). Subplots were composed by absence or presence of straw mulch mechanical management, by horizontal crusher use, 20 days after chemical management. Pearl millet sole crop produced greater amounts of dry matter $\left(14,040 \mathrm{~kg} \mathrm{ha}^{-1}\right)$ and showed higher $\mathrm{K}$ and $\mathrm{Mg}$ concentrations, accumulated greater amounts of nutrients in aboveground. Castor bean grain yield was higher in succession to pigeonpea-pearl millet intercropping. Castor bean grain yield was higher in the absence of straw mulch mechanical management.
\end{abstract}

Key words - Ricinus communis. Cajanus cajan. Nutrients cycling. Pennisetum glaucum. Intercropping. Soil-management.

\footnotetext{
*Autor para correspondência

${ }^{1}$ Recebido para publicação em 10/08/2010; aprovado em 25/05/2011

Parte do trabalho de Iniciação Científica do segundo autor desenvolvido com bolsa FAPESP

2Programa de Pós-Graduação em Agronomia/Agricultura, Faculdade de Ciências Agronômicas, Universidade Estadual Paulista/UNESP, Botucatu-SP, Brasil, jaymeferrari@hotmail.com, c_hideo@hotmail.com

${ }^{3}$ Departamento de Produção Vegetal/Āgricultura, Faculdade de Ciências Agronômicas, Universidade Estadual Paulista/UNESP, Botucatu-SP, Brasil, crusciol@fca.unesp.br; soratto@fca.unesp.br
} 


\section{Introdução}

O Brasil é o terceiro maior produtor de mamona (FAO, 2009), mas possui produtividade média baixa, cerca de $760 \mathrm{~kg} \mathrm{ha}^{-1}$ (CONAB, 2010).

No Estado de São Paulo concentra-se a maior parte das indústrias processadoras de óleo vegetal. $\mathrm{O}$ abastecimento das indústrias paulistas é realizado com produções advindas dos Estados da Bahia, Minas Gerais e importada do Paraguai (KIIHL; SAVY FILHO, 2009), pois o Estado de São Paulo, apesar de apresentar alta produtividade média $\left(1.230 \mathrm{~kg} \mathrm{ha}^{-1}\right)$, contribui com menos de $2 \%$ da produção do país (CONAB, 2010).

Nos últimos anos, têm se desenvolvido novos híbridos e cultivares de mamona de porte baixo adaptados aos sistemas de produção mecanizados e em larga escala, como o sistema plantio direto (SPD).

O SPD promove inúmeros benefícios ao solo, tais como: proteção contra o impacto direto das gotas de chuva, favorecimento da infiltração, redução da perda de água por escoamento superficial e de solo e nutrientes por erosão, aumento da quantidade de matéria orgânica, proporcionando maior disponibilidade de nutrientes às plantas (CALEGARI, 2000). O aumento das opções disponíveis para compor esquemas de rotação, no SPD, constitui-se em um dos pilares para o sucesso deste sistema (CARNEIRO et al., 2008; CRUSCIOL; SORATTO, 2007).

O milheto (Pennisetum glaucum (L.) R. Br.) tem se constituído em uma boa opção de planta de cobertura, fornecendo elevadas quantidades de massa de matéria seca (MS), possibilitando o sucesso do SPD (CARNEIRO et al., 2008; CARVALHO et al., 2004a, 2004b, 2004c; CASTRO, 2009), especialmente em regiões de inverno seco. Espécies com maior relação $\mathrm{C} / \mathrm{N}$, como o milheto, devem ser utilizadas no SPD, pois quanto maior esta relação, mais lenta a decomposição dos resíduos, e maior a proteção do solo (GIACOMINI et al., 2003; TORRES et al., 2008). Leguminosas como o guandu-anão (Cajanus cajan (L.) Millsp.), apesar da menor relação $\mathrm{C} / \mathrm{N}$, possuem capacidade de reciclar elevadas quantidades de nutrientes, podendo fazer parte da rotação, pois promovem a liberação de nutrientes durante a sua decomposição, a qual é mais rápida, proporcionando, assim, benefício em curto prazo (DAROLT, 1998; SALMI et al., 2006; TORRES et al., 2008).

O consórcio de leguminosas com gramíneas de elevada produção de MS, pode conciliar eficiente cobertura vegetal do solo e maior fixação biológica ou reciclagem de nutrientes, principalmente o $\mathrm{N}$ e $\mathrm{K}$ (OLIVEIRA et al., 2002; TEIXEIRA et al., 2005).

$\mathrm{O}$ tipo de manejo pode influenciar a decomposição da palhada e, consequentemente, a liberação de nutrientes para a cultura em sucessão (GIACOMINI et al., 2003).
Porém, o uso de implementos específicos, como o triturador de palha horizontal, pode acarretar desvantagens como, baixo rendimento operacional, alto custo e risco de compactação do solo (DENARDIN; KOCHHANN, 1993). Contudo, pouco se sabe sobre o efeito do tipo de manejo da palhada sobre o desempenho de culturas em sucessão.

Estudos de diferentes coberturas do solo e diversos manejos dapalhadadas coberturasnoSPD sãonecessários, para que se tenha uma maior gama de espécies a serem utilizadas nas rotações, buscando produzir quantidade adequada de MS e liberação de nutrientes para a cultura em sucessão. Assim, o objetivo deste trabalho foi avaliar a produção de MS e o acúmulo de nutrientes do milheto e guandu-anão em cultivo solteiro e consorciado, bem como, o efeito do manejo da palhada destas coberturas do solo, no desempenho da cultura da mamona na safrinha, no estabelecimento do SPD.

\section{Material e métodos}

O experimento foi conduzido na Fazenda Experimental Lageado, da Faculdade de Ciências Agronômicas - UNESP, Botucatu, SP (22 $58^{\prime} \mathrm{S}$ e $48^{\circ} 23^{\prime} \mathrm{W}$ e $765 \mathrm{~m}$ de altitude). O solo do local é um Nitossolo Vermelho, cultivado com cana-de-açúcar até cerca de seis meses antes da instalação do experimento. No inverno de 2004, a área foi cultivada com a cultura da aveia preta, sem adubação. Segundo a classificação climática de Köeppen, o clima predominante na região é do tipo Cwa. É caracterizado pelo clima tropical de altitude, com inverno seco e verão quente e chuvoso. As precipitações pluviais e temperaturas registradas, durante a condução do experimento, são apresentadas na Figura 1.

As características químicas do solo $(0-20 \mathrm{~cm})$ foram determinadas antes da instalação do experimento e os resultados foram: 25,0 $\mathrm{g} \mathrm{dm}^{-3}$ de M.O.; $\mathrm{pH}\left(\mathrm{CaCl}_{2}\right)$ 5,$0 ; 17,0 \mathrm{mg} \mathrm{dm}^{-3}$ de P (resina); 1,6; 33,3; 17,6; 34,1 $\mathrm{mmol}_{\mathrm{c}} \mathrm{dm}^{-3}$ de $\mathrm{K}, \mathrm{Ca}, \mathrm{Mg}$ e $\mathrm{H}+\mathrm{Al}$, respectivamente; e $61 \%$ de saturação por bases. A prática da calagem não foi necessária, pois, de acordo com Savy Filho (1997), para a mamoneira a calagem deve ser realizada para elevar a saturação por bases à $60 \%$ e a concentração de $\mathrm{Mg}$ a um mínimo de $5 \mathrm{mmol} \mathrm{dm}^{-3}$, valores estes inferiores aos observados na análise de solo.

O delineamento experimental adotado foi em blocos casualizados, em esquema de parcelas subdivididas, com quatro repetições. As parcelas foram constituídas por três tipos de cobertura vegetal: guandu-anão - cultivar IAPAR 43Aratã, milheto - cultivar BN-2 e consórcio (guandu-anão + milheto) e as subparcelas foram constituídas pela ausência ou presença do manejo mecânico da palhada, mediante uso de triturador de palha horizontal, 20 dias após manejo químico. Cada subparcela apresentava $5 \mathrm{~m}$ de largura por 15 metros de comprimento, perfazendo uma área total de $75 \mathrm{~m}^{2}$. 


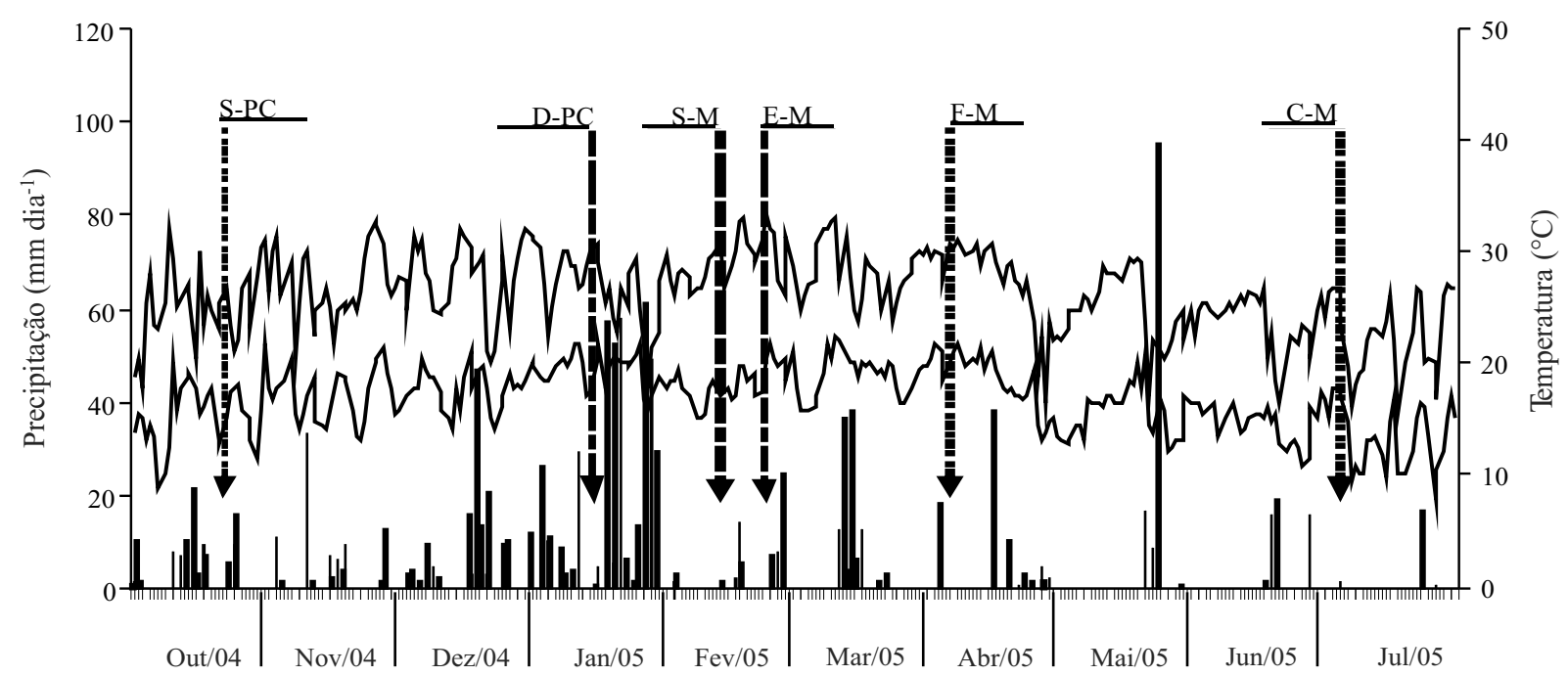

Figura 1 - Precipitação pluvial ( \) temperaturas máxima (-) e mínima $\theta$ obtidas na área experimental durante o período de outubro de 2004 a julho de 2005 em Botucatu (SP). S-PC: semeadura das plantas de cobertura; D-PC: dessecação das plantas de cobertura; S-M: semeadura da mamona; E-M: emergência da mamona; F-M: início do florescimento da mamona; C-M: colheita da mamona

Antes da semeadura das espécies de cobertura, foi realizada a dessecação das plantas presentes na área com a utilização do herbicida glifosato ( $1.920 \mathrm{~g} \mathrm{ha}^{-1}$ i.a.). As espécies de cobertura, guandu-anão e milheto foram semeadas, sem adubação, em 21/10/2004, no espaçamento de $0,17 \mathrm{~m}$ entre linhas e aproximadamente $0,05 \mathrm{~m}$ de profundidade, utilizando 40 e $20 \mathrm{~kg} \mathrm{ha}^{-1}$ de sementes de guandu-anão e milheto, respectivamente. No cultivo consorciado, as sementes das diferentes espécies foram misturadas, na proporção de $20+10 \mathrm{~kg} \mathrm{ha}^{-1}$, respectivamente, de guandu-anão e milheto, também sem adubação, namesma profundidade e espaçamento utilizados para as culturas solteiras. A emergência das plantas ocorreu no dia 30/10/2004.

Aos 75 DAE (dias após a emergência) das culturas de cobertura foi realizada a coleta das plantas de cobertura (14/01/2005), para determinação da produção de MS e concentração de nutrientes na parte aérea. Foram amostrados dois quadros, com $0,25 \mathrm{~m}^{2}$ de área interna (amostras simples), que constituíram uma amostra composta. Os resíduos sofreram pré-limpeza por meio de peneiras, para remoção do solo aderido, em seguida foram lavados, sem o emprego de detergente, agitando-os por alguns segundos em água deionizada, em três porções sucessivas, sendo a seguir colocados sobre papel absorvente. $\mathrm{O}$ material foi seco em estufa com circulação forçada de ar a $60{ }^{\circ} \mathrm{C}$ e pesado. Posteriormente, realizou-se a determinação das concentrações de macronutrientes (N, P, K, Ca, Mg e S), segundo Malavolta et al. (1997), e carbono (C), pelo método de Walkley e Black, descrito por Tedesco et al. (1995). De posse dos resultados, das concentrações de macronutrientes e $\mathrm{C}$, foram calculadas a relação $\mathrm{C} / \mathrm{N}$ e as quantidades de macronutrientes acumuladas por hectare, através da multiplicação da quantidade de MS por hectare pela concentração dos macronutrientes.
Após as coletas, foi realizada a dessecação das plantas com aplicação de glifosato (1.920 $\mathrm{g} \mathrm{ha}^{-1}$ do i.a.). A semeadura da mamona foi realizada no dia 17/02/2005, utilizando-se o híbrido Íris, no espaçamento $0,45 \mathrm{~m}$ entrelinhas e $0,50 \mathrm{~m}$ entre plantas. A adubação mineral de semeadura constou da aplicação de $250 \mathrm{~kg} \mathrm{ha}^{-1}$ da fórmula N-P-K 08-28-16, seguindo as recomendações de Savy Filho (1997). A emergência da cultura ocorreu no dia 23/02/2005.

O híbrido Íris apresenta como principais características: precocidade, floração com 36 DAE, $60 \%$ de plantas femininas, rusticidade, altura média de $1,40 \mathrm{~m}$, fruto indeiscente, boa debulha, sendo adequada para colheita mecanizada com automotriz.

Durante a condução da cultura, não se realizou adubação de cobertura e não houve a necessidade de realização de tratos culturais, como aplicação de defensivos agrícolas.

Por ocasião da colheita da mamona (05/07/2005), foram determinados os componentes da produção (população final de plantas, número de racemos por planta, número de frutos por racemo, número médio de grãos por fruto e massa de cem grãos), e a produtividade de grãos (13\% de umidade).

Os dados obtidos foram submetidos à análise de variância e as médias comparadas por meio do teste de Tukey ao nível de 5\% de significância, utilizando-se o programa estatístico Sisvar.

\section{Resultados e discussão}

O milheto em cultivo solteiro se destacou na produção de MS (14.040 $\mathrm{kg} \mathrm{ha}^{-1}$ ), 127\% superior ao 
consórcio do guandu-anão + milheto $\left(6.195 \mathrm{~kg} \mathrm{ha}^{-1}\right)$ e $197 \%$ maior que o cultivo solteiro do guandu-anão, que produziu $4.720 \mathrm{~kg} \mathrm{ha}^{-1}$ (TAB. 1).

Carvalho et al. (2004a, 2004b, 2004c) observaram produções de MS pelo milheto três vezes maiores que as do guandu-anão, tanto em SPD quanto em sistema de preparo convencional do solo. Crusciol e Soratto (2007) obtiveram produção de $8.909 \mathrm{~kg} \mathrm{ha}^{-1}$ de MS para milheto manejado em fevereiro, 71 dias após a emergência (DAE). Torres et al. (2008) obtiveram produções de MS do milheto da ordem de $10.300 \mathrm{~kg} \mathrm{ha}^{-1}$ quando semeado em agosto, e $3.600 \mathrm{~kg} \mathrm{ha}^{-1}$ quando semeado em abril, ambos manejados aos 110 DAE. Oliveira et al. (2002) obtiveram produção de MS do milheto semelhante a este trabalho, com manejo aos 100 dias após a semeadura, mas estes autores realizaram adubação de semeadura no milheto com $300 \mathrm{~kg} \mathrm{ha}^{-1}$ da fórmula N-P-K 4-30-16. A maior produção de MS do milheto no presente trabalho está relacionada à época de cultivo e, principalmente, à adequada quantidade de chuvas durante o período de desenvolvimento do milheto (FIG.1). Crusciol e Soratto (2009) observaram resultados semelhantes na mesma época de semeadura e período de cultivo.

Aquantidademínimaideal deMS para que semantenha a adequada cobertura do solo é de $6.000 \mathrm{~kg} \mathrm{ha}^{-1}$ (DAROLT, 1998), desta maneira, o guandu-anão não produziu quantidade de MS suficiente (TAB. 1), porém, no consórcio do guanduanão com milheto houve produção de quantidade satisfatória de MS, indicando que o consórcio dessas espécies pode ser opção interessante para a produção de palhada. Teixeira et al. (2005) também obtiveram produção de MS no consórcio guandu-anão + milheto superior a do cultivo do guanduanão solteiro, porém, diferentemente do presente trabalho, os autores não observaram diferenças na produção de MS entre o milheto solteiro e o consórcio. Além disso, os valores observados foram 2.505 e $2.907 \mathrm{~kg} \mathrm{ha}^{-1}$ de MS para o consórcio e milheto, respectivamente, valores estes, inferiores aos do presente trabalho, devido à época de cultivo (março). Torres et al. (2008) observaram produções de MS do guandu-anão da ordem de 1.600 e $2.700 \mathrm{~kg} \mathrm{ha}^{-1}$, com manejo da fitomassa aos 110 DAE. Porém, produções de MS pelo guandu-anão entre 4.670 e $5.950 \mathrm{~kg} \mathrm{ha}^{-1}$ também foram encontradas por Salmi et al. (2006). No entanto, é importante destacar que fatores como a época de semeadura e manejo, fertilidade do solo e condições climáticas interferem diretamente na produção de MS das coberturas vegetais do solo (CRUSCIOL; SORATTO, 2007; CRUSCIOL; SORATTO, 2009; TORRES et al., 2008).

Quanto às concentrações de nutrientes na MS das plantas de cobertura, foi constatado no milheto as maiores concentrações de $\mathrm{K}, \mathrm{Mg}$ e S (TAB. 1). No guandu-anão, verificaram-se maiores concentrações de $\mathrm{N}$ e Ca. Teixeira et al. (2005) também observaram maiores concentrações de $\mathrm{K}$ e $\mathrm{Mg}$ no milheto e de $\mathrm{N}$ e $\mathrm{C}$ no guandu-anão. Não houve diferença entre as coberturas vegetais, com relação à concentração de $\mathrm{P}$ na MS parte aérea das coberturas vegetais. Concentrações intermediárias de N, K, Ca, Mg e S foram observadas na palhada do cultivo consorciado. Com exceção das concentrações de $\mathrm{Ca}$ e $\mathrm{Mg}$, as concentrações dos demais macronutrientes na parte aérea do milheto, no presente estudo, foram superiores aos observados por Crusciol e Soratto (2007), que encontraram 13,3; 1,5; 13,9; 5,2; 3,2 e 3,6 $\mathrm{g} \mathrm{kg}^{-1}$ de N, P, K, Ca, Mg e S, respectivamente. Castro (2009), também avaliando a concentração de macronutrientes do milheto no primeiro corte, conduzido durante a safrinha e manejado aos 50 DAE, verificou valores de $\mathrm{N}\left(30,89 \mathrm{~g} \mathrm{~kg}^{-1}\right)$ e $\mathrm{Ca}\left(4,77 \mathrm{~g} \mathrm{~kg}^{-1}\right)$ superiores, e de $\mathrm{P}\left(1,88 \mathrm{~g} \mathrm{~kg}^{-1}\right), \mathrm{K}\left(5,27 \mathrm{~g} \mathrm{~kg}^{-1}\right), \mathrm{Mg}\left(2,88 \mathrm{~g} \mathrm{~kg}^{-1}\right) \mathrm{e}$ $\mathrm{S}\left(1,76 \mathrm{~g} \mathrm{~kg}^{-1}\right)$ inferiores aos valores encontrados neste trabalho.

Tabela 1 - Massa de matéria seca, concentração de macronutrientes e relação $\mathrm{C} / \mathrm{N}$ na parte aérea das plantas de cobertura. Botucatu (SP), 2004/05

\begin{tabular}{|c|c|c|c|c|c|c|c|c|}
\hline \multirow{3}{*}{ Tratamento } & \multirow{2}{*}{ Matéria seca } & \multicolumn{6}{|c|}{ Concentração na parte aérea } & \multirow{3}{*}{ Relação C/N } \\
\hline & & $\mathrm{N}$ & $\mathrm{P}$ & $\mathrm{K}$ & $\mathrm{Ca}$ & $\mathrm{Mg}$ & $\mathrm{S}$ & \\
\hline & $\left(\mathrm{kg} \mathrm{ha}^{-1}\right)$ & \multicolumn{6}{|c|}{ - } & \\
\hline Guandu & $4.720 \mathrm{c}$ & $28,3 \mathrm{a}$ & $2,6 \mathrm{a}$ & $11,0 \mathrm{c}$ & $8,3 \mathrm{a}$ & $2,0 \mathrm{c}$ & $1,5 \mathrm{~b}$ & $30,8 \mathrm{~b}$ \\
\hline Milheto & $14.040 \mathrm{a}$ & $16,2 \mathrm{~b}$ & $2,7 \mathrm{a}$ & $23,0 \mathrm{a}$ & $4,0 \mathrm{c}$ & $3,5 \mathrm{a}$ & $2,5 \mathrm{a}$ & $47,8 \mathrm{a}$ \\
\hline Guandu + milheto & $6.195 \mathrm{~b}$ & $18,3 \mathrm{~b}$ & $2,3 \mathrm{a}$ & $19,6 \mathrm{~b}$ & $6,8 \mathrm{~b}$ & $2,5 \mathrm{~b}$ & $2,2 \mathrm{a}$ & $44,3 \mathrm{a}$ \\
\hline Teste $\mathrm{F}$ & $1346,97 * *$ & $5,15 * *$ & $0,93^{\text {ns }}$ & $31,74 * *$ & $16,32 * *$ & $21,00 * *$ & $11,56^{* *}$ & $4,87^{*}$ \\
\hline $\mathrm{CV}(\%)$ & 3,3 & 15,8 & 18,5 & 12,3 & 16,9 & 12,5 & 14,6 & 6,7 \\
\hline
\end{tabular}

Médias seguidas por letras iguais, na coluna, não diferem entre si pelo de Tukey $(\mathrm{P} \neq 0,05)$. **, * e ns são respectivamente, significativo ao nível de $1 \%, 5 \%$ e não significativo pelo teste $\mathrm{F}$ 
Quanto à relação $\mathrm{C} / \mathrm{N}$, o milheto e o cultivo consorciado produziram os maiores valores, com tendência da relação $\mathrm{C} / \mathrm{N}$ da cobertura consorciada ser menor do que a do milheto, visto que a palhada do cultivo solteiro de guandu-anão apresentou a menor relação C/N (TAB. 1).

Carneiro et al. (2008) também observaram relação $\mathrm{C} / \mathrm{N}$ no milheto superior ao guandu-anão, sendo os valores de 38 e 21 para milheto e guandu-anão, respectivamente, porém, ambas as espécies exibiram valores menores que no presente estudo (TAB. 1). Giacomini et al. (2003) afirmam que quanto maior a relação $\mathrm{C} / \mathrm{N}$, mais lenta a taxa de decomposição dos resíduos, sendo, portanto, mais lenta a liberação dos nutrientes acumulados na palhada das culturas, modificando assim a época da disponibilização dos elementos absorvidos pelas plantas de cobertura.

$\mathrm{O}$ milheto apresentou as maiores quantidades acumuladas de N, P, K, Ca, Mg e S (227,3; 38,5; 321,3; 56,5; 47,5; e 34,8 $\mathrm{kg} \mathrm{ha}^{-1}$, respectivamente) (TAB. 2). O cultivo consorciado acumulou quantidades intermediárias e o cultivo solteiro de guandu-anão acumulou as menores quantidades dos nutrientes, com exceção do $\mathrm{N}$ que foi acumulado em quantidades intermediária no guanduanão solteiro. As quantidades acumuladas pelo milheto, especialmente de $\mathrm{N}$ e $\mathrm{K}$, são superiores às observadas por Crusciol e Soratto $(2007 ; 2009)$. A palhada do milheto acumulou as maiores quantidades de nutrientes, devido à maior produção de MS. Estas características de elevada produção de MS e elevado acúmulo de nutrientes na parte aérea por plantas de cobertura são desejáveis no SPD (CARNEIRO et al., 2008; CRUSCIOL; SORATTO, 2009). Torres et al. (2008), utilizando o milheto como cobertura de solo, relataram acúmulo de $\mathrm{N}$ da ordem de $165,6 \mathrm{~kg} \mathrm{ha}^{-1}$ para uma produção de MS de $10.300 \mathrm{~kg} \mathrm{ha}^{-1}$, na primavera (agosto-novembro) e de $55,8 \mathrm{~kg} \mathrm{ha}^{-1}$ para uma produção de MS de $3.600 \mathrm{~kg} \mathrm{ha}^{-1}$, no outono (abril-julho). Carneiro et al. (2008) verificaram acúmulo de $233 \mathrm{~kg} \mathrm{ha}^{-1}$ de $\mathrm{N}$ pelo milheto, contra $442 \mathrm{~kg} \mathrm{ha}^{-1}$ pelo guandu, semeados em março. Oliveira et al. (2002) relataram que o cultivo solteiro de milheto e o consórcio deste com mucuna-preta destacaram-se quanto ao acúmulo de macronutrientes a serem fornecidos ao solo para o cultivo seguinte, em relação a outras coberturas do solo.

As características agronômicas da cultura da mamona não foram influenciadas pela interação entre os fatores plantas de cobertura e manejo mecânico da palhada (TAB. 3). Dessa forma, foram discutidos apenas os efeitos dos fatores isolados.

A ausência de manejo mecânico da cobertura vegetal, com triturador de palha, proporcionou maior população final de plantas (TAB. 3). Isso pode ter ocorrido devido às menores variações na temperatura e manutenção do teor de água do solo, proporcionada pela ausência de manejo mecânico, que provavelmente favoreceu a emergência e o estabelecimento das plântulas, num período de altas temperaturas e poucas precipitações (FIG. 1).

Com relação ao efeito das plantas de cobertura sobre componentes de produção da mamoneira, cultivada em sucessão, observou-se que somente a variável racemos por planta foi afetada, sendo que o cultivo consorciado de guandu-anão + milheto resultou em maiores valores, e isto refletiu em maior produtividade da mamoneira neste tratamento (TAB. 3). Tal resultado pode estar relacionado com a adequada cobertura do solo e liberação de nutrientes, entre eles $\mathrm{N}$ e K, da cobertura do consórcio para o sistema, devido à quantidade de MS produzida e principalmente à relação $\mathrm{C} / \mathrm{N}$ (TAB. 1). A palhada produzida pelo consórcio, possivelmente, promoveu disponibilidade destes elementos de maneira gradual, fornecendo-os em momentos cruciais do desenvolvimento da mamoneira em sucessão, como o início do desenvolvimento vegetativo e florescimento. Para Giacomini et al. (2003), além de proteger o solo e adicionar $\mathrm{N}$, o consórcio entre espécies de plantas de cobertura deve proporcionar uma produção de

Tabela 2 - Quantidade de macronutrientes acumulada na parte aérea das espécies de cobertura. Botucatu (SP), 2004/05

\begin{tabular}{|c|c|c|c|c|c|c|}
\hline \multirow{3}{*}{ Tratamento } & \multicolumn{6}{|c|}{ Quantidade acumulada na parte aérea } \\
\hline & $\mathrm{N}$ & $\mathrm{P}$ & $\mathrm{K}$ & $\mathrm{Ca}$ & $\mathrm{Mg}$ & $\mathrm{S}$ \\
\hline & 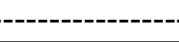 & ----------" & ---- $(\mathrm{kg} \mathrm{h}$ & --- & -------- & -------- \\
\hline Guandu & $134,8 \mathrm{~b}$ & $12,3 \mathrm{~b}$ & $50,5 \mathrm{c}$ & $38,5 \mathrm{~b}$ & $9,8 \mathrm{c}$ & $7,5 \mathrm{c}$ \\
\hline Milheto & $227,3 \mathrm{a}$ & $38,5 \mathrm{a}$ & $321,3 \mathrm{a}$ & $56,5 \mathrm{a}$ & $47,5 \mathrm{a}$ & $34,8 \mathrm{a}$ \\
\hline Guandu + milheto & $113,3 \mathrm{~b}$ & $14,3 \mathrm{~b}$ & $120,0 \mathrm{~b}$ & $41,3 \mathrm{~b}$ & $15,5 \mathrm{~b}$ & $13,8 \mathrm{~b}$ \\
\hline Teste $\mathrm{F}$ & $15,93 * * *$ & $23,03 * *$ & $296,07 * *$ & $7,84^{*}$ & $305,49 * *$ & $103,87 * *$ \\
\hline CV $(\%)$ & 13,1 & 28,1 & 10,0 & 15,3 & 9,6 & 15,0 \\
\hline
\end{tabular}

Médias seguidas por letras iguais, na coluna, não diferem entre si pelo de Tukey $(\mathrm{P}=0,05)$.***, **, * e ns são respectivamente, significativo ao nível de $0,1 \%, 1 \%, 5 \%$ e não significativo pelo teste $\mathrm{F}$ 
Tabela 3 - População final de plantas, número de racemos por planta, número de frutos por racemo, número de grãos por fruto, massa de 100 grãos e produtividade de grãos da cultura da mamona, cultivada no sistema plantio direto em sucessão a diferentes plantas de cobertura, sem e com manejo mecânico da palhada. Botucatu (SP), 2004/05

\begin{tabular}{|c|c|c|c|c|c|c|}
\hline \multirow{2}{*}{ Tratamentos } & \multirow{2}{*}{ População final } & Racemos por & Frutos por & Grão por & Massa de & Produtividade de \\
\hline & & planta & racemo & frutos & 100 grãos & grãos \\
\hline Planta de cobertura $(\mathrm{P})$ & $\mathrm{pl} \mathrm{ha}^{-1}$ & \multicolumn{3}{|c|}{--------------- número ----------------- } & $\mathrm{g}$ & $\mathrm{kg} \mathrm{ha}^{-1}$ \\
\hline Guandu & $37.222 \mathrm{a}$ & $1,9 \mathrm{~b}$ & $27,0 \mathrm{a}$ & $2,9 \mathrm{a}$ & $38,4 \mathrm{a}$ & $2.191 \mathrm{~b}$ \\
\hline Milheto & $37.593 \mathrm{a}$ & $1,9 \mathrm{~b}$ & $27,0 \mathrm{a}$ & $3,0 \mathrm{a}$ & $40,3 \mathrm{a}$ & $2.129 \mathrm{~b}$ \\
\hline Guandu + milheto & $37.037 \mathrm{a}$ & $2,2 \mathrm{a}$ & $26,0 \mathrm{a}$ & $2,9 \mathrm{a}$ & $39,4 \mathrm{a}$ & $2.316 \mathrm{a}$ \\
\hline \multicolumn{7}{|c|}{ Manejo mecânico (M) } \\
\hline Sem & $39.012 \mathrm{a}$ & $1,9 \mathrm{a}$ & $27,1 \mathrm{a}$ & $3,0 \mathrm{a}$ & $40,2 \mathrm{a}$ & $2.410 \mathrm{a}$ \\
\hline Com & $35.556 \mathrm{~b}$ & $2,0 \mathrm{a}$ & $26,0 \mathrm{a}$ & $2,9 \mathrm{a}$ & $38,5 \mathrm{a}$ & $2.014 \mathrm{~b}$ \\
\hline \multicolumn{7}{|c|}{ Teste $\mathrm{F}$} \\
\hline$P$ & $1,69^{\mathrm{ns}}$ & $3,27^{*}$ & $0,52^{\text {ns }}$ & $0,16^{\mathrm{ns}}$ & $0,89^{\text {ns }}$ & $7,44^{*}$ \\
\hline M & $9,96^{*}$ & $1,20^{\text {ns }}$ & $0,59^{\text {ns }}$ & $0,15^{\mathrm{ns}}$ & $1,74^{\mathrm{ns}}$ & $30,53^{* *}$ \\
\hline $\mathrm{P} \times \mathrm{M}$ & $2,43^{\mathrm{ns}}$ & $1,09^{\text {ns }}$ & $0,09^{\text {ns }}$ & $0,35^{\mathrm{ns}}$ & $0,74^{\text {ns }}$ & $3,01^{\mathrm{ns}}$ \\
\hline CV(\%)parcela & 1,7 & 13,0 & 11,2 & 6,3 & 7,3 & 4,5 \\
\hline CV(\%)subparcela & 7,2 & 9,4 & 13,4 & 5,4 & 8,3 & 7,9 \\
\hline
\end{tabular}

Médias seguidas por letras iguais, na coluna, dentro de cada fator, não diferem entre si pelo de Tukey $(\mathrm{P}=0,05) . * *$, e ns são respectivamente, significativo ao nível de $1 \%, 5 \%$ e não significativo pelo teste $\mathrm{F}$

matéria seca cuja relação $\mathrm{C} / \mathrm{N}$ seja intermediária àquela das espécies em culturas isoladas, proporcionando cobertura de solo por mais tempo e sincronia entre fornecimento e demanda de nutrientes pelas culturas comerciais.

No cultivo consorciado houve efeito benéfico das duas espécies de cobertura, pois o milheto por ser uma planta com alta capacidade de reciclar nutrientes do solo, principalmente K (CRUSCIOL; SORATTO, 2007; CRUSCIOL; SORATTO, 2009), e o guandu altamente eficiente em fixar o $\mathrm{N}$ atmosférico (CARNEIRO et al., 2008), proporcionaram suprimento mais equilibrado de nutrientes em relação aos demais tratamentos. $\mathrm{O} \mathrm{K}$ possui papel importante na formação dos frutos, atuando no transporte de fotoassimilados no floema. A deposição de biomassa no fruto é acompanhada, necessariamente, pelo acúmulo de K (MARSCHNER, 1995). Já a ausência do N impede o crescimento inicial da planta (MALAVOLTA et al., 1997), e a frutificação, quando ocorre, é fraca com poucos racemos por planta. A mamoneira é exigente em boa nutrição, na maioria das etapas do seu ciclo de vida (SEVERINO et al., 2006a). Diniz Neto et al. (2009) relataram aumento no número de racemos por planta em função do aumento dos níveis de adubação com NPK, e enfatizaram a importância da manutenção da umidade no início do crescimento da cultura da mamona, pois, desta forma poderá haver maior número de estruturas reprodutivas. Assim, o consórcio pode ter aliado os efeitos benéficos da manutenção da umidade do solo e disponibilidade de nutrientes resultando em mais racemos por planta e, consequentemente, maior produtividade de grãos da mamoneira (TAB. 3).

O manejo das coberturas vegetais com triturador de palha resultou em menor população final de plantas, reduzindo, consequentemente, a produtividade de grãos (TAB.3).Comojádiscutido, onãoesfacelamentodapalhada pode ter favorecido menores variações na temperatura e manutenção do teor de água do solo, promovendo melhor emergência e estabelecimento das plântulas, num período de altas temperaturas e poucas precipitações (FIG. 1). Além disso, provavelmente, o maior tráfego de máquinas, com o uso do triturador de palha horizontal, tenha levado o solo a apresentar maior compactação, prejudicando alguns parâmetros físicos do solo. Segundo Denardin e Kochhann (1993), o uso de implementos específicos ao manejo da palhada de plantas de cobertura pode acarretar desvantagens, tais como: alto custo, baixo rendimento operacional e riscos de compactação do solo, além de esfacelar os resíduos, tornando-os mais suscetíveis ao processo de decomposição.

As produtividades de grãos obtidas nas três coberturas do solo estudadas são consideradas elevadas, pois Silva et al. (2007) obtiveram produtividade média da mamoneira cultivada em SPD da ordem de $1.291 \mathrm{~kg} \mathrm{ha}^{-1}$. 
Severino et al. (2006b) relataram produtividade da mamoneira da ordem de 750 a $950 \mathrm{~kg} \mathrm{ha}^{-1}$.

O presente estudo demonstrou maior produtividade da mamoneira de porte baixo em sucessão ao consórcio de guandu-anão + milheto (TAB. 3). Contudo, outros estudos sobre o efeito de coberturas do solo sobre a nutrição e produtividade da mamoneira devem ser incentivados, afim de que se tenham mais informações sobre plantas de cobertura a serem utilizadas para o cultivo dessa oleaginosa em sucessão, no SPD.

\section{Conclusões}

1.O milheto solteiro produz maior quantidade de MS e apresenta maiores concentrações de $\mathrm{K} \mathrm{e} \mathrm{Mg}$;

2.O milheto solteiro acumula maiores quantidades de macronutrientes na parte aérea do que o guandu-anão solteiro ou o consórcio guandu-anão + milheto;

3.O número de racemos por planta e a produtividade de grãos da mamoneira são maiores em sucessão ao consórcio guandu-anão + milheto;

4. A produtividade de grãos da mamoneira é maior na ausência do manejo mecânico da palhada.

\section{Agradecimentos}

À Fapesp, pelo financiamento do projeto e concessão de bolsa de Iniciação Científica ao primeiro autor e ao CNPq pela concessão de bolsa de produtividade ao segundo e terceiro autores.

\section{Referências}

CALEGARI, A. Rotação de cultura. In: Guia para plantio direto. Ponta Grossa: FEBRAPDP, 2000. p. 68-78.

CARNEIRO, M. A. C. et al. Produção de fitomassa de diferentes espécies de cobertura e suas alterações na atividade microbiana de solo de cerrado. Bragantia, v. 67, n. 02, p. 455-462, 2008.

CARVAlHO, M. A. C. et al. Soja em sucessão a adubos verdes no sistema de plantio direto e convencional em solo de Cerrado. Pesquisa Agropecuária Brasileira, v. 39, n. 11, p. 1141-1148, 2004a.

CARVALHO, M. A. C. et al. Adubação verde e sistemas de manejo do solo na produtividade do algodoeiro. Pesquisa Agropecuária Brasileira, v. 39, n. 12, p. 1205-1211, 2004 b.
CARVALHO, M. A. C. et al. Produtividade do milho em sucessão a adubos verdes no sistema de plantio direto e convencional. Pesquisa Agropecuária Brasileira, v. 39, n. 01, p. 47-53, 2004c.

CASTRO, G. S. A. Alterações físicas e químicas do solo em função do sistema de produção e da aplicação superficial de silicato e calcário. 2009. 135 f. Dissertação (Mestrado em Agronomia/Agricultura) - Universidade Estadual Paulista, Faculdade de Ciências Agronômicas, Botucatu.

CONSELHO NACIONAL DE ABASTECIMENTO (CONAB). Comparativo Safras: Série histórica. Disponível em: $<\mathrm{http}: / /$ www.conab.gov.br>. Acesso em: 12 fev. 2010.

CRUSCIOL,C.A.C.; SORATTO, R.P. Nutriçãoe produtividade do amendoim em sucessão ao cultivo de plantas de cobertura no sistema plantio direto. Pesquisa Agropecuária Brasileira, v. 42, n. 11, p. 1553-1560, 2007.

CRUSCIOL, C. A. C.; SORATTO, R. P. Nitrogen supply for cover crops and effects on peanut grown in succession under a no-till system. Agronomy Journal, v. 101, p. 41-46, 2009.

DAROLT, M. R. Princípios para implantação e manutenção do sistema. In: DAROLT, M.R. Plantio direto: pequena propriedade sustentável. Londrina: IAPAR, 1998. p. 16-45.

DENARDIN, J. E.; KOCHHANN, R. A. Requisitos para implantação e a manutenção do sistema plantio direto. In: Plantio Direto no Brasil. Passo Fundo: Aldeia Norte. EMBRAPA-CNPT;FECOTRIGO-FUNDACEP;FUNDAÇÃO ABC, 1993. p. 19-27.

DINIZ NETO, M. A. et al. Adubação NPK e épocas de plantio para mamoneira. II - Componentes das fases vegetativas e reprodutivas. Revista Ciência Agronômica, v. 40, n. 03, p. 417- 426, 2009.

FOOD AGRICULTURE ORGANIZATION (FAO) Production and trade - Castor beans, 2007. Disponível em: <http://faostat.fao.org>. Acesso em: 09 dez. 2009.

GIACOMINI, S. J. et al. Matéria seca, relação $\mathrm{C} / \mathrm{N}$ e acúmulo de nitrogênio, fósforo e potássio em misturas de plantas de cobertura de solo. Revista Brasileira de Ciência do Solo, v. 27, n. 02, p. 325-334, 2003.

KIIHL, T. A. M.; SAVY FILHO, A. Cultura da mamona: o que falta para crescer? In: CÂMARA, G. M. S. (Coord.). Soja \& Cia. Piracicaba, 2009. p. 53-69.

MALAVOLTA, E.; VITTI, G. C.; OLIVEIRA, S. A. de. Avaliação do estado nutricional das plantas: princípios e aplicações. 2. ed. Piracicaba: POTAFOS, 1997. 319 p.

MARSCHNER, H. Mineral nutrition of higher plants. 2. ed. London: Academic Press, 1995. 889 p.

OLIVEIRA, T. K.; CARVAlHO, G. J.; MORAES, R. N. S. Plantas de cobertura e seus efeitos sobre o feijoeiro em plantio direto. Pesquisa Agropecuária Brasileira, v. 37, n. 08, p. 1079-1087, 2002.

SALMI, G. P.; SALMI, A. P.; ABBOUD, A. C. S. Dinâmica de decomposição e liberação de nutrientes de genótipos de guandu sob cultivo em aléias. Pesquisa Agropecuária Brasileira, v. 41, n. 04, p. 673-678, 2006. 
SAVY FILHO, A. Mamona. In: RAIJ, B. van; et al. Recomendações de adubação e calagem para o Estado de São Paulo. 2. ed. Campinas: Instituto Agronômico e Fundação IAC, 1997. p. 201 (Boletim técnico, 100).

SEVERINO, L. S. et al. Otimização do espaçamento de plantio para a mamoneira cultivar BRS Nordestina. Revista Brasileira de Oleaginosas e Fibrosas, v. 10, p. 993-999, 2006a.

SEVERINO, L. S. et al. Crescimento e produtividade da mamoneira adubada com macronutrientes e micronutrientes. Pesquisa Agropecuária Brasileira, v. 41, n. 04, p. 563-568, 2006b.
SILVA, T. R. B. et al. Adubação nitrogenada em cobertura na cultura da mamona em plantio direto. Pesquisa Agropecuária Brasileira, v. 42, n. 09, p. 1357-1359, 2007.

TEDESCO, M. J., GIANELLO, C., BISSANI, C. Análise de solo, plantas e outros materiais. 2. ed. Porto Alegre: Departamento de Solos da UFRGS, 1995. 174 p. (Boletim Técnico, 5).

TEIXEIRA, C. M. et al. Produção de biomassa e teor de macronutrientes do milheto, feijão-de-porco e guandu-anão em cultivo solteiro e consorciado. Ciência e Agrotecnologia, v. 29, n. 01, p. 93-99, 2005.

TORRES, J. L. R.; PEREIRA, M. G.; FABIAN, A. J. Produção de fitomassa por plantas de cobertura e mineralização de seus resíduos em plantio direto. Pesquisa Agropecuária Brasileira, v. 43, n. 03, p. 421-428, 2008. 